\section{Vinte e quatro meses de heterocontrole da fluoretação das águas de abastecimento público de Pelotas, Rio Grande do Sul, Brasil}

\author{
Twenty-four months of external control \\ of fluoride levels in the public water supply \\ in Pelotas, Rio Grande do Sul, Brazil
}

Fábio Garcia Lima 1 Rafael Guerra Lund 1 Lídia Morales Justino 2 Flávio Fernando Demarco 1 Francisco Augusto Burkert Del Pino 1 Rinaldo Ferreira 2

\title{
Introdução
}

1 Faculdade de Odontologia, Universidade Federal de Pelotas, Pelotas, Brasil.

2 Faculdade de Odontologia, Universidade do Vale do Itajaí, Itajaí, Brasil.

Correspondência Fábio Garcia Lima Av. José Maria da Fontoura 399, Pelotas, RS 96090-370, Brasil. fgarcial@ufpel.tche.br

\section{Abstract}

The aim of the present study was monthly evaluation of fluoride levels in the public water supply in Pelotas, Rio Grande do Sul State, Brazil, and the validity of forming external control groups. Pelotas was divided into 16 geographic regions, including the three public water treatment stations. Water samples were collected from November 1999 to October 2001. Two samples were drawn from each region. Samples were sent to the Fluoride Health Surveillance Laboratory at Universidade do Vale do Itajaí. Fluoride analysis used an electrometric method (Orion 920 A/Electrometer Orion 9609). After 24 months, 764 samples were collected, demonstrating a discontinuity in the fluoride levels. There was an increase in the number of samples with an ideal concentration of fluoride. However, several points with excessive fluoride levels (>0.9ppmF) also appeared. Based on these results it was concluded that external control is essential for monitoring fluoride levels in the public water supply.

Fluorine; Fluoridation; Water Treatment; Surveillance
A fluoretação das águas de abastecimento público é reconhecida como uma das mais importantes medidas de Saúde Pública e prevenção de doenças de todos os tempos 1,2. Graças a esta iniciativa e outros fatores, como a utilização de dentifrícios fluoretados e a implantação de programas de prevenção nas escolas, a população tem assistido a um decréscimo na prevalência de cárie 3 .

A adição de flúor à água de beber é efetiva na prevenção da cárie dental 4,5 e continua sendo a medida de maior alcance populacional, bem como a melhor forma de garantir uma igualdade social em termos de saúde odontológica 1,2.

Para que a Fluoretação das Águas de Abastecimento Público (FAAP) tenha máxima eficiência, os níveis de flúor devem estar dentro do chamado "nível ótimo" e de forma ininterrupta por longos períodos 6,7,8,9,10,11. Para assegurar tal condição, o controle externo da FAAP por diferentes grupos sociais ("heterocontrole”) faz-se necessário 10, uma vez que somente o controle interno pode ser ineficiente 12 , devido ao método utilizado 13 ou à carência de pessoal devidamente treinado 14. Barros et al. 15 mostraram a inadequação dos teores de flúor na água de abastecimento público de Porto Alegre, Rio Grande do Sul, num período de análise de 13 anos, o que reafirma a importância do heterocontrole. 
A primeira cidade do mundo a implantar um sistema de fluoretação da água foi o Município de Grand Rapids, Estados Unidos, em 19452,4 , gerando efeitos até hoje vistos tanto na saúde pública quanto na prática odontológica 16. No Brasil, a fluoretação das águas teve início em 1953, no Município de Baixo Guandu, Espírito Santo.

A FAAP como método de prevenção é recomendada pela Associação Dentária Americana desde 1950 e pela Organização Mundial da Saúde desde 1969 e, no Brasil, existem a Lei 6.050 e o Decreto 76.872 de 1975 17, determinando a obrigatoriedade da implantação do método em nosso país, além de ser apoiada por todas as associações de classe da Odontologia brasileira 18 .

O Rio Grande do Sul foi o primeiro Estado a possuir uma legislação determinando a obrigatoriedade da adição de flúor às águas de abastecimento público. A cidade de Taquara foi o primeiro local do estado a receber os benefícios da fluoretação, em 195715.

Partindo desses princípios, o objetivo do presente trabalho foi o de monitorar por 24 meses o nível de flúor (F-) adicionado à água de abastecimento público da cidade de Pelotas, Rio Grande do Sul, Brasil e avaliar a validade da formação de grupos de "heterocontrole".

\section{Material e método}

Este estudo foi realizado em uma cidade do interior do Rio Grande do Sul, onde a fluoretação das águas de abastecimento público ainda consiste na medida de maior alcance populacional em termos de Saúde Bucal Coletiva.

Pelotas é a maior cidade da Zona Sul do Estado e abriga uma população de aproximadamente 323.158 habitantes (segundo dados da Prefeitura Municipal dessa cidade).

De acordo com o censo realizado de agosto a dezembro de 2000, pela agência local da Fundação Instituto Brasileiro de Geografia e Estatística, Pelotas é uma cidade cuja zona urbana comporta 297.825 habitantes e 92.274 domicílios, dos quais, 87.990 recebem água canalizada em pelo menos um cômodo. Ou seja, o abastecimento de água atinge parcela significativa do perímetro urbano: $97,15 \%$ (89,6 mil) dos domicílios na zona urbana contam com rede de abastecimento, alcançando, na área delimitada como centro uma porcentagem de $99,05 \%$ dos domicílios assistidos. Dos 297.825 moradores do perímetro urbano, $60 \%$ da população está na faixa etária entre 0 e 39 anos, e 8,51\% (25,3 mil) dos 10 aos 14 anos.

A realização deste trabalho teve o apoio do órgão responsável pelo tratamento da água de abastecimento público, o Serviço Autônomo de Saneamento de Pelotas, solicitando informações pertinentes à pesquisa, como o número de Estações de Tratamento de Água (ETAs), que são três: ETA Santa Bárbara, responsável pelo tratamento de cerca de $70 \%$ do volume da água consumida na cidade; ETA Moreira e ETA Sinnotti.

A verificação do teor de flúor na água foi feita pelo Laboratório de Vigilância Sanitária de Flúor da Faculdade de Odontologia da Universidade do Vale do Itajaí (UNIVALI), em Itajaí, Santa Catarina.

O mapeamento dos pontos de coleta levou em conta o número de habitantes abastecidos pela água tratada (cidades com mais de $200 \mathrm{mil}$ habitantes - mínimo de 15 pontos de coleta, segundo as normas do laboratório da UNIVALI).

A coleta foi realizada mensalmente, de maneira uniforme ao longo do período de $24 \mathrm{me}$ ses 19,20, em duplicata, desde novembro de 1999 até outubro de 2001, obtendo-se assim 12 coletas anuais 10. As unidades amostrais foram coletadas em frascos de $5 \mathrm{ml}$ previamente esterilizados, com calor úmido, nas três ETAs (para verificar possíveis perdas da concentração de flúor ao longo da rede de distribuição) e em mais 13 pontos diferentes abastecidos por estas, totalizando 16 pontos de coleta, divididos geograficamente de maneira que abrangesse todas as regiões da cidade 20. Estes eram situados, preferencialmente, em locais públicos, como escolas, postos de saúde e hospitais e todos eram pontos finais da rede de distribuição, diretamente de torneiras, onde é efetivamente realizado o consumo 10

Em 24 meses de coleta, em duplicata, nos 16 pontos estabelecidos, foram coletadas 48 unidades amostrais em cada, exceção feita às ETAs Sinnotti e Santa Bárbara, onde não foi possível efetuar a coleta em abril de 2001 (46 análises), o que totalizou 764 unidades amostrais coletadas, mensuradas e analisadas.

Todas as coletas foram realizadas na primeira semana de cada mês, num único dia, pela manhã e o envio ao Laboratório de Vigilância Sanitária do Flúor da UNIVALI foi feito no mesmo dia à tarde. A mensuração dos níveis de flúor na água foi no máximo sete dias após a coleta, o que não altera os resultados, uma vez 
que não há variação dos mesmos quando fechados em frascos plásticos num período de até 150 dias 21 .

O método de mensuração usado pelo laboratório foi o eletrométrico, realizado por meio de eletrodo combinado seletivo para flúor (Orion 9609) e por potenciômetro (Orion 920A). A cada mês, antes e após terem sido feitas as análises, eram realizadas contraprovas com solução padrão de fluoreto de sódio pró-análise e água miliQ $\left(\mathrm{H}_{2} \mathrm{O}\right.$ Millipore System - Alemanha), na concentração de $2 \mathrm{ppmF}$.

No Município de Pelotas, as primeiras adições de flúor nas ETAs tiveram início em maio de 1961. O sal de flúor usado é o fluossilicato de sódio, adicionado à água nas três ETAs através de tanque "em fibra" dosador de flúor. Calvo 12 verificou que $97,3 \%$ dos municípios que adicionavam flúor às suas águas elegiam o ácido fluossilícico como composto fluoretante, por ser de mais barata obtenção, porém tem seu transporte dificultado em virtude de se apresentar no estado líquido, sendo mais recomendado para sistemas situados próximos às fontes produtoras, o que não seria o caso de Pelotas, conforme explica Pinto 22, pois essas fontes localizam-se nos Estados de São Paulo e Minas Gerais.

A concentração de flúor na água, ideal à prevenção da doença cárie segue a Portaria no10/99 da Secretaria Municipal de Saúde de Porto Alegre 23, que aceita como níveis acessíveis de flúor valores na faixa de 0,6 a $0,9 \mathrm{ppm}$, sendo $0,8 \mathrm{ppm}$ o teor considerado ideal. Este intervalo de concentrações foi adotado para todo o Rio Grande do Sul e define os teores aceitáveis na água de beber oferecida pelo sistema de abastecimento público.

\section{Resultados}

A Tabela 1 revela a descontinuidade dos teores de flúor dissolvido nos 16 pontos monitorados, após o período de 24 meses de acompanhamento. Por outro lado, a média da grande maioria dos respectivos locais estudados estava dentro do padrão aceitável.

Na Figura 1, observa-se um significativo aumento no número de unidades amostrais com uma concentração de flúor ótima (0,6-0,9ppmF), ao longo dos 24 meses de análise. Mas, em contrapartida, tem-se o surgimento de inúmeros pontos revelando um excesso de fluoretos (> 1ppmF).

A Figura 2 revela uma grande oscilação na quantidade de flúor presente na água que é distribuída pelas ETAs. E observa-se que esta variação mensal da concentração ocorre tanto

Resultados das análises de flúor após 24 meses de heterocontrole.

\begin{tabular}{|c|c|c|c|c|}
\hline Local de coleta (pontos) & Meses & $\begin{array}{l}\text { Total de } \\
\text { amostras }\end{array}$ & $\begin{array}{l}\text { PpmF Mediana } \\
\text { (mín.-máx.) }\end{array}$ & $\begin{array}{l}\text { PpmF Média } \\
\text { (desvio padrão) }\end{array}$ \\
\hline 1. ETA Moreira & 24 & 48 & $0,82(0,22-1,72)$ & $0,83(0,30)$ \\
\hline 2. ETA Sinnotti & $23^{*}$ & 46 & $0,74(0,08-1,11)$ & $0,71(0,24)$ \\
\hline 3. ETA Santa Bárbara & $23^{*}$ & 46 & $0,62(0,07-1,32)$ & $0,64(0,31)$ \\
\hline 4. CIEP Fragata & 24 & 48 & $0,65(0,46-0,97)$ & $0,65(0,14)$ \\
\hline 5. Escola Estadual Adolfo Fetter & 24 & 48 & $0,59(0,28-0,84)$ & $0,59(0,17)$ \\
\hline 6. Posto de Saúde Municipal Central & 24 & 48 & $0,63(0,23-0,96)$ & $0,62(0,19)$ \\
\hline 7. Hospital Universitário & 24 & 48 & $0,56(0,19-0,99)$ & $0,63(0,24)$ \\
\hline 8. Parque Municipal da Baronesa & 24 & 48 & $0,65(0,24-0,98)$ & $0,66(0,19)$ \\
\hline 9. Escola Municipal Ginásio do Areal & 24 & 48 & $0,69(0,09-1,04)$ & $0,68(0,21)$ \\
\hline $\begin{array}{l}\text { 10. Escola Municipal Dom Campos } \\
\text { de Mendes Barreto }\end{array}$ & 24 & 48 & $0,72(0,06-1,13)$ & $0,73(0,20)$ \\
\hline 11. Reservatório do Balneário Barro Duro & 24 & 48 & $0,71(0,64-0,85)$ & $0,72(5,48 E-02)$ \\
\hline 12. Associação Rural de Pelotas & 24 & 48 & $0,60(0,19-0,96)$ & $0,59(0,21)$ \\
\hline 13. Escola Municipal Antônio & 24 & 48 & $0,54(0,23-1,02)$ & $0,58(0,23)$ \\
\hline 14. Igreja Evangélica Martinho Lutero & 24 & 48 & $0,81(0,05-1,26)$ & $0,82(0,26)$ \\
\hline 15. Posto Municipal Ercy Ribeiro & 24 & 48 & $0,77(0,05-1,29)$ & $0,79(0,24)$ \\
\hline 16. Residência Ana Terra & 24 & 48 & $0,59(0,24-1,16)$ & $0,64(0,24)$ \\
\hline
\end{tabular}

* No mês de abril de 2001, não foi possível coletar água em duas das três Estações de Tratamento, justificando o fato das ETA's Sinnoti e Santa Bárbara apresentarem somente 23 meses de heterocontrole. 


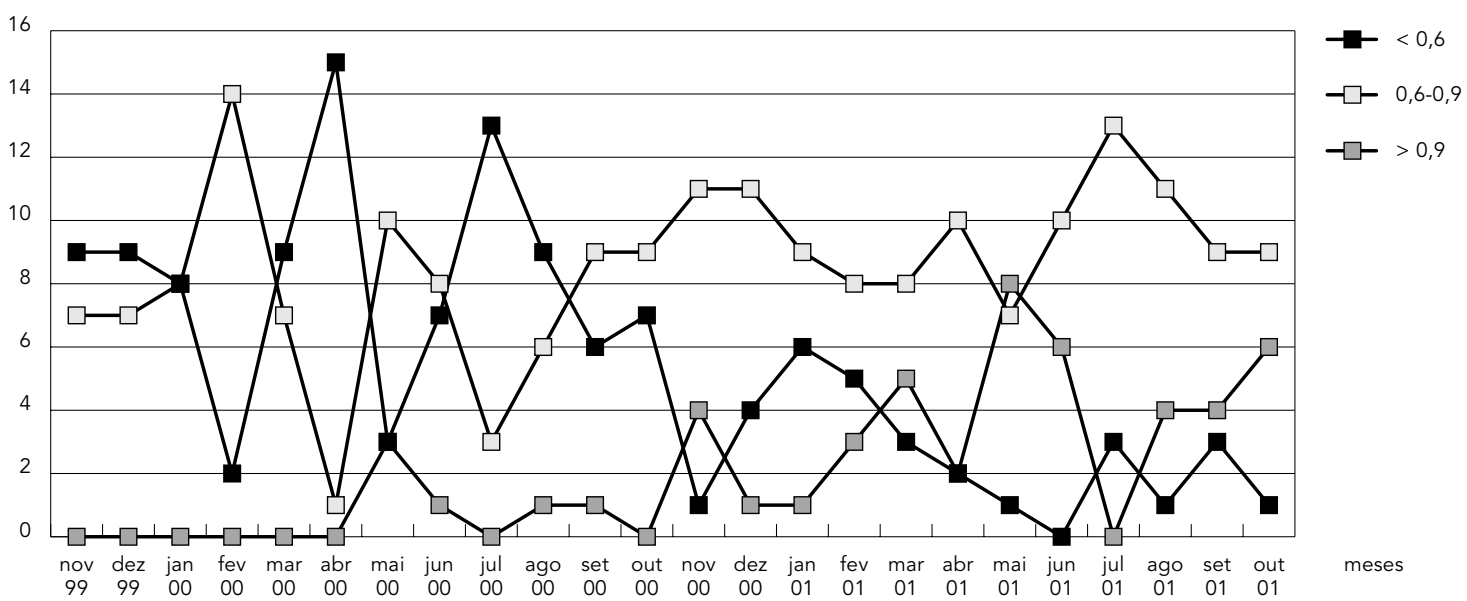

nas ETAs menores (Moreira e Sinotti), quanto na principal ETA da cidade (Santa Bárbara).

Nenhum dos locais da cidade de Pelotas apresentou todas as amostras coletadas nos 24 meses com uma concentração de flúor adequada, conforme demonstra a Figura 3.

\section{Discussão}

Dentre os métodos de aplicação de flúor, a FAAP se apresenta como eficaz, barato e de grande caráter social 1,2, sendo considerada nos Estados Unidos como uma das dez principais medidas de saúde pública do século 2024 .

Sua efetividade é facilmente justificada quando entendemos que subdosagens de flúor (subppmF-) são suficientes para minimizar o processo de desmineralização, bem como acelerar o processo de remineralização 25 .

Muitos são os motivos que levaram a um declínio da cárie dentária em nível mundial, tais como o avanço de materiais e técnicas, programas de prevenção e, de maior abrangência, a FAAP. Porém, para tal método ter efetividade é necessário estar nos níveis calculados como ótimos e de forma contínua 6,7,8,9,11.

Ao analisarmos a situação de Pelotas, nossos resultados demonstram que, além de aproximadamente $50 \%$ dos pontos de coleta apresentarem níveis não ótimos de flúor, há uma grande variação em cada ponto ao longo dos 24 meses, havendo assim a interrupção do programa, tornando-o menos efetivo à prevenção da doença cárie.

\section{Figura 2}

Concentrações de flúor nas ETA's.

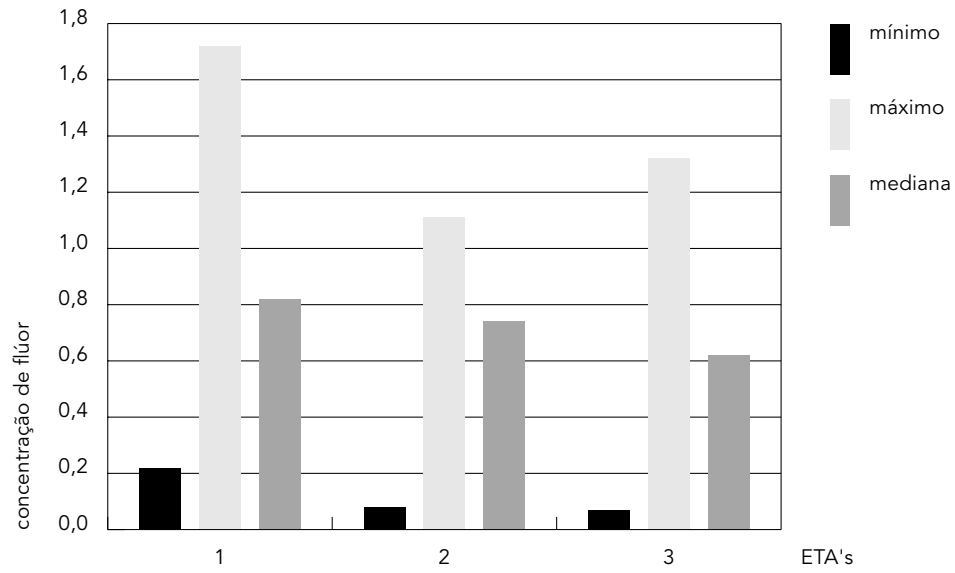

Infelizmente, a constância do teor mensal de flúor foi praticamente impossível de ser alcançada em qualquer estação de tratamento de água, conforme demonstra a Figura 1. Uma oscilação na concentração ótima de fluoreto dissolvido, de 0,1 a $0,2 \mathrm{mg} / \mathrm{l}$, sempre existiu, e diversos são os fatores que podem levar a isso, como: falta de treinamento do operador responsável pela fluoretação, problemas no equipamento hidráulico ou variações no fluxo de 
água (vazão) ao longo da rede de distribuição da cidade 14 . Pelotas tem uma planta de distribuição hidráulica muito complexa e cerca de 11 reservatórios de água suspeitos de variar a dosagem de flúor nos pontos de consumo final, em virtude da alteração da vazão durante o trajeto da água encanada.

Pôde-se observar que dos 16 pontos analisados, o reservatório do Balneário "Barro Duro" (ponto 11) foi o único que apresentou uma certa constância na média de flúor mensal e, portanto, um baixo desvio padrão. Isso é devido ao fato de que se trata do único local da região urbana da cidade onde o flúor presente na água é de ocorrência natural, pois esta região não é abastecida por nenhuma das três ETAs da cidade.

Também é importante ressaltar neste estudo que as avaliações das concentrações de fluoretos basearam-se na Portaria no 10/99 23, adotada para todo o Estado do Rio Grande do Sul. Poderia ter sido utilizada a Portaria no 635-BsB do Ministério da Saúde, de dezembro de 1975, 26 onde a concentração de flúor ideal, para a água de abastecimento público, é dependente da média das temperaturas máximas diárias do ar em cada região e, neste caso, os resultados seriam diferentes. No entanto, a Portaria no 36/MS/GM 19, de 19 de janeiro de 1990, ratificada pela Portaria no $1.469,20$ de 29 de de- zembro de 2000, afirma que devem ser seguidos os valores de concentração de fluoretos atendendo à legislação em vigor, ou seja, a Portaria no 10/99 23 .

Vários trabalhos são encontrados na literatura demonstrando a eficiência da FAAP na redução da incidência da doença cárie. Basting et al. 7, num trabalho realizado na cidade de $\mathrm{Pi}$ racicaba, São Paulo, após 25 anos de FAAP, comprovam que houve uma redução de $79 \%$ da incidência de cárie em escolares, mostrando a eficiência de tal método, quando bem empregado e controlado. De maneira similar, em Campinas, São Paulo, Viegas \& Viegas 11, após 14 anos de FAAP, verificaram uma redução na prevalência de cárie de $57 \%$ para dentes permanentes e de $49 \%$ nos dentes decíduos, em crianças entre 4 e 14 anos. Oliveira et al. 9, após 18 anos de FAAP em Belo Horizonte, Minas Gerais, relataram uma redução no índice CPO-D de 44,46\% em escolares de 6 a 12 anos, mas ressaltam que, como método isolado de prevenção, tem limitações na eficácia. No Município de Birigui, São Paulo, Moimaz et al. 27 encontraram uma redução de $47,64 \%$ e 30,9\% nos índices CPOD e Ceo, respectivamente, após dez anos de fluoretação.

Para que haja uma maior efetividade na prevenção da doença cárie é interessante que

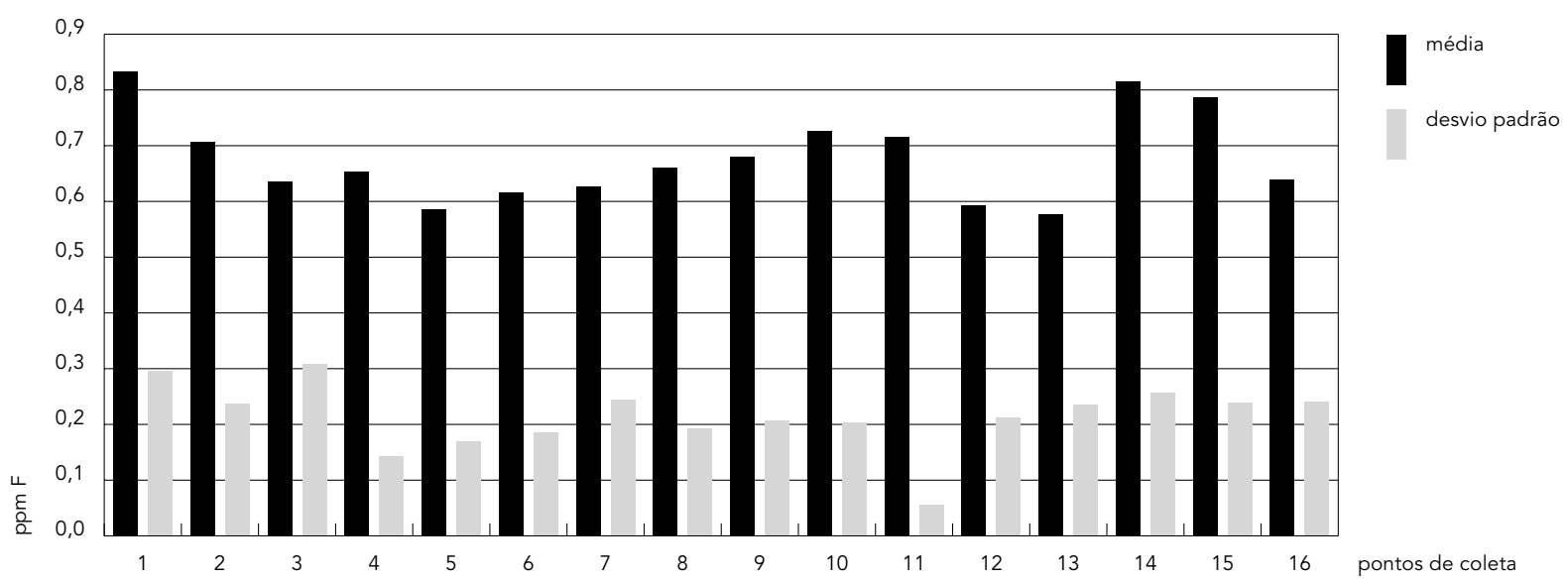

Pontos de coleta: 1 - ETA Santa Bárbara; 2 - ETA Sinnotti; 3 - ETA Moreira; 4 - CIEP Fragata; 5 - Escola Estadual Adolfo Fetter; 6 - Posto de Saúde Municipal Central; 7 - Hospital Universitário; 8 - Parque Municipal da Baronesa; 9 - Escola Municipal Ginásio do Areal; 10 - Escola Municipal Dom Campos de Mendes Barreto; 11 - Reservatório do Balneário Barro Duro; 12 - Associação Rural de Pelotas; 13 - Escola Municipal Antônio; 14 - Comunidade Evangélica Martinho Lutero; 15 - Posto Municipal Ercy Ribeiro; 16 - Residencial Ana Terra.

ETA 1: 48 unidades amostrais coletadas; ETA 2: 46 unidades amostrais coletadas; ETA 3: 46 unidades amostrais coletadas. 
as crianças sejam beneficiadas de água fluoretada desde o nascimento 28 .

Na verdade, o efeito da adição de fluoreto na água de beber é difícil de ser determinado nos dias de hoje, visto que milhares de produtos fluoretados estão à disposição da população, tornando difusa e diluída a sua ação perante a atividade dos demais veículos de flúor: dentifrícios fluoretados, flúor tópico aplicado pelo dentista, colutórios, suplementos de flúor na dieta, além de alimentos e bebidas, como chás, sucos e águas minerais 2 . No entanto, a FAAP continua sendo talvez a única forma de prevenção à saúde bucal disponível à população de mais baixa renda, predominante no Brasil 29 por isso verificamos resultados tão significantes em nosso país.

Em países desenvolvidos, cuja maior parte da população utiliza dentifrícios fluoretados e é beneficiada por outros programas de prevenção, o índice de cárie é relativamente baixo, bem como a principal preocupação com os dentes passou a ser a erosão dental 30 , fazendo com que programas de fluoretação pareçam não apresentar grandes benefícios, conforme demonstrou Seppä et al. 31, na Finlândia, que constataram uma pequena diferença (24\%) na incidência de cárie entre as cidades de Kuopio (com FAAP) e Jyväskyla (sem FAAP). Maupomé et al. 32 , na cidade de British Columbia, Canadá, comparando os índices de cárie de uma área com água fluoretada e outra onde havia cessado a fluoretação, não verificaram diferenças estatisticamente significantes entre as duas regiões. Não é o caso do Brasil, um país em desenvolvimento, com carência de um completo programa de prevenção à saúde 29 . Justifica-se ainda a FAAP em virtude dos custos públicos, onde dar atendimento à população com necessidades restauradoras é muito mais oneroso ao Estado 1,33,34.

Comunidades que dispõem de água fluoretada têm um índice muito menor de cárie e uma alta porcentagem populacional de crianças livres desta doença, mesmo quando fatores considerados confundidores, como status social, sexo ou idade, são controlados 35.

Além disso, em virtude do grande uso de flúor nas suas mais diversas formas, é indispensável que haja um controle da prevalência de fluorose dental em todas as comunidades, independente de possuírem água fluoretada ou não. Pelotas, onde aproximadamente $25 \%$ da população é composta por crianças que dispõem de água fluoretada, a dose total de flúor ingerida deve ser controlada principalmente quanto à quantidade de dentifrício fluoretado que é colocada na escova infantil 36 .
Somando-se a isso, a quantidade de flúor ótima na água de beber deveria ser estipulada, baseando-se num estudo prévio de todas as fontes fluoretadas disponíveis em cada comunidade 37 .

Antifluoretacionistas defenderam uma redução na dosagem de flúor ideal que era adicionada artificialmente em níveis naturais inferiores de ocorrência na água, argumentando apresentar a mesma eficácia e a diminuição do risco de fluorose dental nestas áreas 38 . Porém, Newbrum 39 já alertava sobre os constantes ataques desferidos por esses contra esta consagrada medida preventiva, na tentativa de atemorizar de alguma forma a população.

Muito tem sido enfatizado a respeito do aumento da prevalência de fluorose com os programas de fluoretação e, conseqüentemente, os gastos que surgiriam com tratamentos restauradores odontológicos para solucionar problemas estéticos. Mas os argumentos econômicos que defendem a fluoretação são muito superiores aos possíveis malefícios que possam existir em decorrência da ingestão excessiva de fluoretos 1 .

A otimização dos níveis de flúor nas ETAs por meio do heterocontrole continua sendo uma das medidas mais eficazes de saúde publica 6,8. Um parecer técnico do Comitê TécnicoCientífico de Saúde Bucal do Ministério da Saúde afirma que não fluoretar a água ou interromper sua continuidade deve ser considerado uma atitude juridicamente ilegal, cientificamente insustentável e socialmente injusta e, para garantir os benefícios deste método com segurança em relação à fluorose dental recomendase, em primeiro lugar, oficializar um programa de heterocontrole da concentração de flúor na água 18.

No Município de Pelotas, por exemplo, a simples adição de flúor à água de beber, estava demonstrando excesso nos últimos meses, o que nos leva a presumir que, caso continue, poderá ocorrer um crescimento da incidência de fluorose dental na população juvenil daqui a alguns anos, apesar de que, para se considerar a água potável, o valor máximo permitido de flúor é de $1,5 \mathrm{mg} / 1$ 20, o que muito raramente ocorreu.

A FAAP quando feita de maneira correta é por excelência um método preventivo à cárie dentária comprovadamente eficaz por suas vantagens. Todavia, da maneira que está sendo executada na cidade de Pelotas é mais um exemplo de gastos indevidos do dinheiro público, da mesma forma que, se continuarem alguns pontos com excesso de flúor, poderá ocorrer uma maior incidência de fluorose dentária. Isso comprova a importância do "hetero- 
controle" da FAAP, uma vez que se não tivesse existido, muito provavelmente a adição de flúor na água de beber poderia continuar sendo negligenciada sem o conhecimento de terceiros, interessados na manutenção de um efetivo programa de FAAP, bem como é de extrema importância a tomada de providências visando a modificação do quadro atual.

\section{Conclusões}

Dentro das limitações do estudo, após 24 meses de análise, foi possível concluir que: (1) o heterocontrole é essencial em Pelotas, uma vez que os níveis de flúor na água variaram demasiadamente ao longo do período de monitoramento; (2) o heterocontrole deve continuar enquanto houver FAAP em Pelotas; (3) os níveis de flúor apresentam-se mais compatíveis com aqueles preconizados ao final do período de avaliação, porém, a sua variabilidade continua elevada, prejudicando o efeito preventivo do método no controle da cárie dental e aumentando os riscos de fluorose.
Resumo

O objetivo deste estudo foi monitorar, mensalmente,os níveis de flúor na água de abastecimento público de Pelotas, Rio Grande do Sul, Brasil, bem como verificar a validade da formação de grupos de heterocontrole. Pelotas foi dividida em 16 pontos geográficos, incluindo as três Estações de Tratamento da água e a coleta foi feita de novembro de 1999 a outubro de 2001, em duplicata. Após a coleta, as amostras foram enviadas ao Laboratório de Vigilância Sanitária de Flúor da Universidade do Vale do Itajaí, onde a análise foi feita utilizando-se o método eletrométrico (Orion 920A/Eletrodo Orion 9609). Após 24 meses, 764 unidades amostrais foram coletadas e verificou-se uma inconstância nos resultados, predominando níveis insuficientes de flúor até o primeiro trimestre de 2001, quando houve um significativo aumento no número de unidades amostrais com uma concentração de flúor ideal $(0,6$ 0,9 ppmF),porém, há o surgimento de pontos revelando um excesso de fluoretos ( $>1 \mathrm{ppmF}$ ). Os resultados permitiram concluir que o heterocontrole é fundamental para buscar a manutenção de um correto programa de FAAP.

Flúor; Fluoração; Tratamento da Água; Vigilância

\section{Colaboradores}

F. G. Lima contribuiu com a elaboração do projeto de pesquisa, realizou as coletas d'água por um período de 12 meses, acompanhou os demais 12 meses, redigiu o manuscrito e realizou correções no segundo momento. R. G. Lund participou da coleta das amostras nos demais 12 meses e, conjuntamente, da redação do manuscrito. L. M. Justino colaborou na confecção do projeto e nas análises de flúor. F. F. Demarco contribuiu na orientação do trabalho e executou correções no projeto e no manuscrito. F. A. B. Del Pino e R. Ferreira colaboraram nas análises de flúor.

\section{Agradecimentos}

Agradecemos à Fundação de Amparo à Pesquisa do Estado do Rio Grande do Sul.

\section{Referências}

1. McNally M, Downie J. The ethics of water fluoridation. J Can Dent Assoc 2000; 66:592-3.

2. Horowitz HS. The effectiveness of community water fluoridation in the United States. J Public Health Dent 1996; 56:253-8.

3. Cury JA. Uso do flúor e o controle da cárie como doença. In: Baratieri LN, Monteiro S, Andrada MAC, Vieira LCC, Ritter AV, Cardoso AC, organizadores. Odontologia restauradora - fundamentos e possibilidades. São Paulo: Editora Santos; 2001. p. 34-68.

4. Scott DB. The dawn of a new era. J Public Health Dent 1996; 56:235-8.

5. Stevens RE. Fluoridation and the private practice of dentistry. J Public Health Dent1996;56:239-41.

6. Tsutsui A, Yagi M, Horowitz AM. The prevalence of dental caries and fluorosis in Japanese communities with up to $1,4 \mathrm{ppm}$ of naturally occuring fluoride. J Public Health Dent 2000; 60:147-53.

7. Basting RT, Pereira AC, Meneghim MC. Avaliação da prevalência de cárie dentária em escolares do Município de Piracicaba, SP, Brasil, após 25 anos de fluoretação das águas de abastecimento público. Rev Odontol Univ São Paulo 1997; 11:287-92.

8. Cortes DF, Ellwood RP, O'Mullane DM, Bastos JRM. Drinking water fluoride levels, dental fluorosis, and caries experience in Brazil. J Public Health Dent 1996; 56:226-8.

9. Oliveira CMB, Assis DF, Ferreira EF. Avaliação da fluoretação da água de abastecimento público de Belo Horizonte, MG, após 18 anos. Revista do Conselho Regional de Odontologia de Minas Gerais 1995 ; 1:62-6. 
10. Schneider Filho DA, Prado IT, Narvai PC, Barbosa SE. Fluoretação da água. Como fazer a vigilância sanitária? Rio de Janeiro: Rede CEDROS; 1992. (Série Cadernos de Saúde Bucal 2).

11. Viegas Y, Viegas AR. Prevalência de cárie dental na Cidade de Campinas, SP, Brasil, depois de quatorze anos de fluoretação da água de abastecimento público. Rev Assoc Paul Cir Dent 1985; 39:272-82.

12. Calvo MCM. Situação da fluoretação de águas de abastecimento público no Estado de São PauloBrasil [Dissertação de Mestrado]. São Paulo: Faculdade de Saúde Pública, Universidade de São Paulo; 1996.

13. Maia LC, Valença AMG, Soares EL, Cury JA. Controle operacional da fluoretação da água de Niterói, Rio de Janeiro, Brasil. Cad Saúde Pública 2003; 19:61-7.

14. Lalumandier JA, Hernandez LC, Locci AB, Reeves TG. US drinking water: fluoridation knowledge level of water plant operators. J Public Health Dent 2001; 61:92-8.

15. Barros ERC, Tovo MF, Scapini C. Análise crítica da fluoretação de águas no Município de Porto Alegre/RS. RGO 1990; 38:247-54.

16. Burt BA. Fifty years of water fluoridation. Br Dent J 1995; 21:49-50.

17. Decreto no 76.872 . Regulamenta a Lei no 6.050 de 21 de maio de 1971. Dispõe sobre a fluoretação de sistemas públicos de abastecimento. Diário Oficial da União 1975; $22 \mathrm{dez}$.

18. Ministério da Saúde. Parecer técnico de 24 de agosto de 1999, do Comitê Técnico-Científico (CTC) de assessoramento à área técnica de saúde bucal do Ministério da Saúde, DF, Brasil, com o objetivo de esclarecer seu posicionamento técnico-científico sobre o método de fluoretação da água de abastecimento público. Brasília: Ministério da Saúde; 1999.

19. Ministério da Saúde. Portaria no 36/MS/GM, de 19 de janeiro de 1990. Aprova as normas e o padrão de potabilidade da água destinada ao consumo humano. Brasília: Ministério da Saúde; 1990.

20. Ministério da Saúde. Portaria no 1.469 , de 29 de dezembro de 2000. Estabelece os procedimentos e responsabilidades relativos ao controle e vigilância da qualidade da água para consumo humano e seu padrão de potabilidade, e dá outras providências. Brasília: Ministério da Saúde;2000.

21. Prado IAT, Beevmlieri CM, Narvai PC, Schneider DA, Manfredini MA. Estabilidade do flúor em amostras de água. RGO 1992; 40:197-9.

22. Pinto VG. A odontologia no município: guia para organização de serviços e treinamento de profissionais em nível local. Porto Alegre: RGO; 1996.

23. Secretaria de Estado da Saúde do Rio Grande do Sul. Portaria no 10/99, de 16 de agosto de 1999. Define teores de concentração do íon fluoreto nas águas para consumo humano fornecidas por Sistemas Públicos de Abastecimento. Porto Alegre: Secretaria de Estado da Saúde do Rio Grande do Sul; 1999.
24. Centers for Disease Control and Prevention. Recomendations for using fluoride to prevent and control dental caries in the United States. MMWR 2001; 50:1-42.

25. Ten Cate JM. Current concepts on the theories of the mechanism of action of fluoride. Acta Odontol Scand 1999; 57:322-9.

26. Ministério da Saúde. Portaria no 635-BsB. Aprova normas e padrões sobre a fluoretação da água, tendo em vista a lei no 6.050/74. Diário Oficial da União 1975; 26 dez.

27. Moimaz SAS, Saliba NA, Arcieri RM, Saliba O, Sundefeld MLMM. Redução na prevalência da cárie dentária, após dez anos de fluoretação da água de abastecimento público, no Município de Birigui, SP, Brasil. Rev Faculdade Odontol Lins 1995; 8:41-5.

28. Maltz M, Schoenardie AB, Carvalho JC. Dental caries and gingivitis in schoolchildren from the municipality of Porto Alegre, Brazil in 1975 and 1996. Clin Oral Investig 2001; 5:199-204.

29. Pinto VG. Prevenção da cárie dental. In: Pinto VG, organizador. Promoção de saúde bucal. São Paulo: Editora Santos; 2000. p. 353-401.

30. Ten Cate JM. What dental diseases are we facing in the new millennium: some aspects of the research agenda. Caries Res 2001; 35 Suppl 1:2-5.

31. Seppä L, Kärkkäinen S, Hausen H. Caries frequency in permanent teeth before and after discontinuation of water fluoridation in Kuopio, Finland. Community Dent Oral Epidemiol 1998; 26:256-62.

32. Maupomé G, Clark DC, Levy SM, Berkowitz J. Patterns of dental caries following the cessation of water fluoridation. Community Dent Oral Epidemiol 2001; 29:37-47.

33. Griffin SO, Jones K, Tomar SL. An economic evaluation of community water fluoridation. J Public Health Dent 2001; 61:78-86.

34. Forss H. Efficiency of fluoride programs in the light of reduced caries levels in young populations. Acta Odontol Scand 1999; 57:348-51.

35. Gillcrist JA, Brumley DE, Blackford JU. Community fluoridation status and caries experience in children. J Public Health Dent 2001; 61:168-71.

36. Lima YBO, Cury JA. Ingestão de flúor por crianças pela água e pelo dentifrício. Rev Saúde Pública 2001; 35:576-81.

37. Villa AE, Guerrero S, Villalobos J. Estimation of optimal concentration of fluoride in drinking water under conditions prevailing in Chile. Community Dent Oral Epidemiol 1998; 26:249-55.

38. Limeback H. Recent studies confirm old problems with water fluoridation: a fresh perspective. Fluoride 2001; 34:1-6.

39. Newbrun E. The fluoridation war: a scientific dispute or a religious argument? J Public Health Dent 1996; 56:246-52.

Recebido em 15/Abr/2003

Versão final reapresentada em 28/Ago/2003

Aprovado em 18/Set/2003 